\title{
أهم الحرف والصناعات في إقليم قورينة في العصر البيزنطي في ضوء رسائل لسينسيوس القوريني
}

\author{
د. ش. شكري يوسف شكري \\ دكتوراه - كلية الآداب - جامعة الإسكندرية
}

يهتم هذا البحث بدراسة أهم الحرف والصناعات في إقليم قورينة في العصر البيزنطي

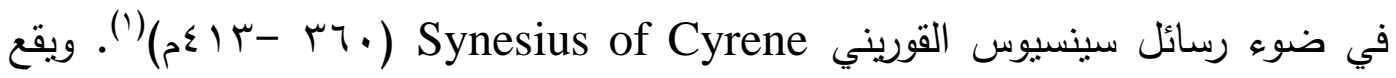
إقليم قورينة Cyrene بشرق ليييا على هضبة مستوية تتجه من الثرق إلى الغرب، وتتحدر بثدة باتجاه الثمال، حيث يوجد ساحل البحر المتوسط، ويحده من ناحية الثرق مرتفعات

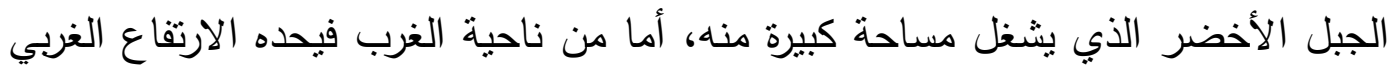

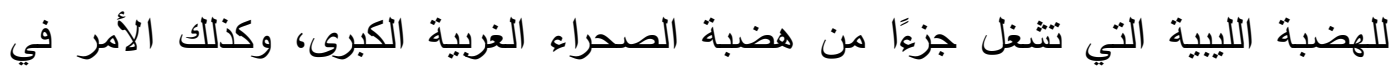

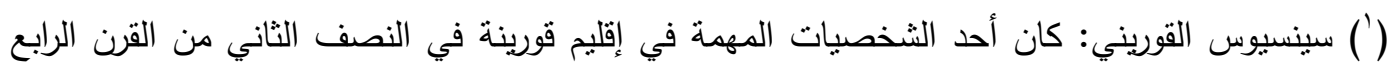

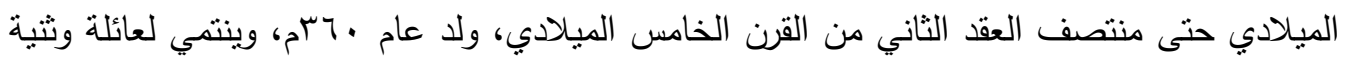

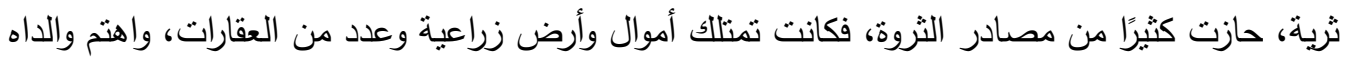

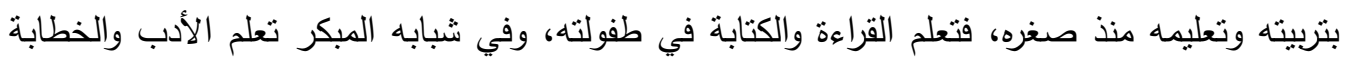

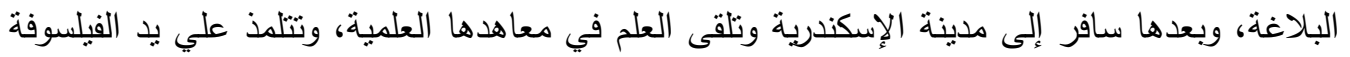

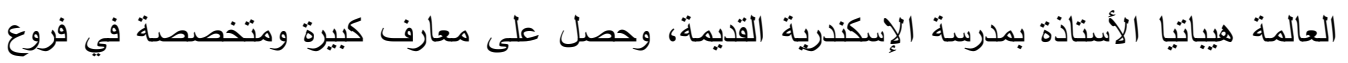

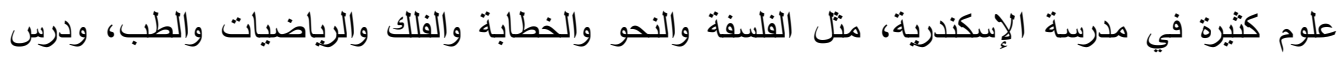

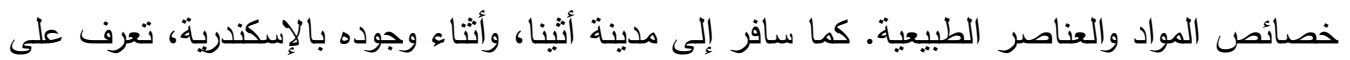

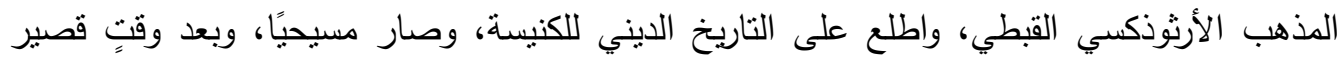

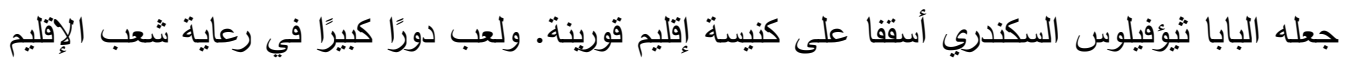

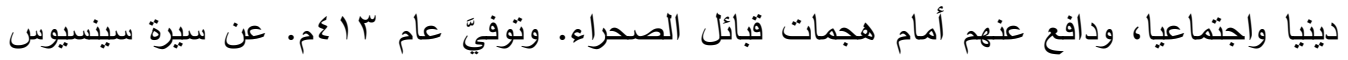
القوريني راجع: دائيا واجناءيا ود

Alice Gardner, Synesius of Cyrene, London, 1886; Crawford, W.S., Synesius the Hellene, London, 1901; Nicol, J. C., Senysius of Cyrene: His Life And Writings, Cambridge, 1887; Bregman, J., Synesius of Cyrene, Philosopher and Bishop, California, 1982.

ميخائيل مكسي إسكندر : تاريخ الدسيحية وآثارها في الذصس مدن الغربية، ط r، القاهرة، ه. بام، ص $. T \cdot T-r A v$ 
ناحيته الجنوبية. وقد جاء الإغريق إليها من جزيرة ثيرا Thera، والتي تعرف حاليًا باسم

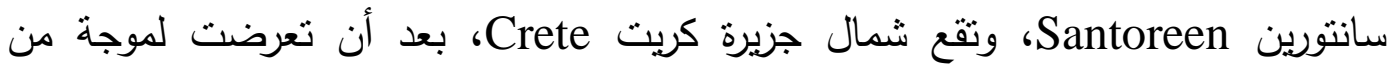

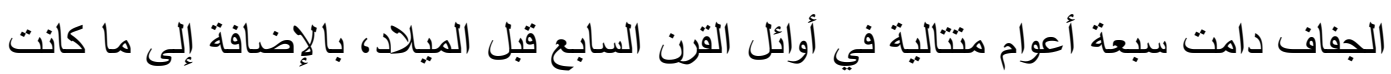

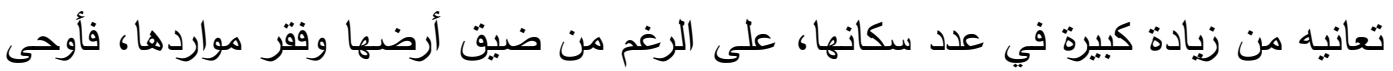
إليهم كهنة دعبد دلفي Delphi بالهجرة إلى الساحل الليبيَ القريب منهم لعلهم يجدون ظروفًا أفضل للحياة هناك، وبالفعل تحركوا إلى الساحل الليبيَ، وأقاموا بالجبل الأخضر

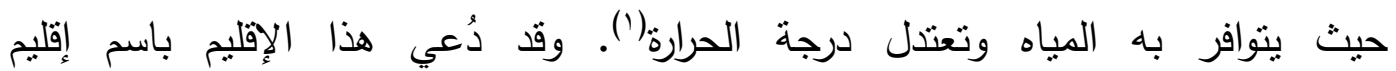
بنتابوليس Pentapolis، وهي تسمية يونانية تعني إقليم الخمس مدن، والمقصود بها المدن

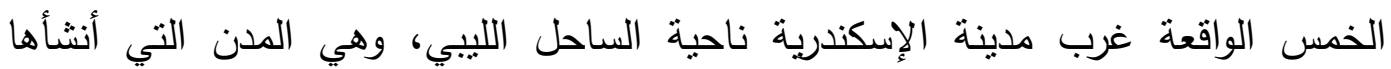

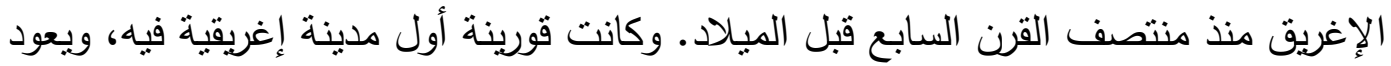

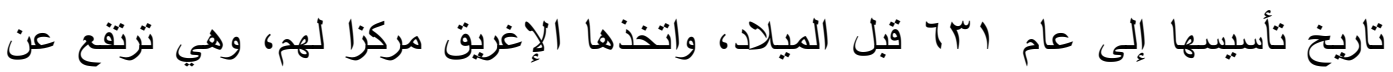
سطح البحر نحو ستمائة متر، وتبتعد ثلاثة عشر كيلو متر عنه، وتبتعد نحو ثمانية عشر الإنا كيلو مترات إلى الجنوب من مينائها أبولونيا Apollonia الواقع على ساحل البحر

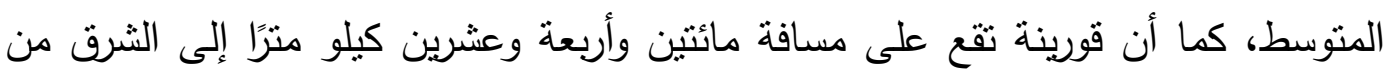
مدينة بنغازي الحالية، وتشرف على الطريق الرئيس الممهد بين مصر وبلاد المغرب العربيَ،

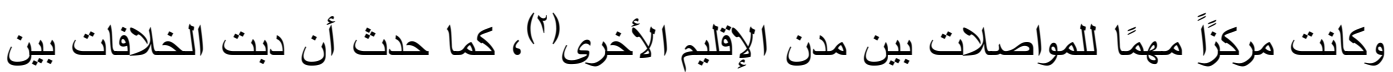

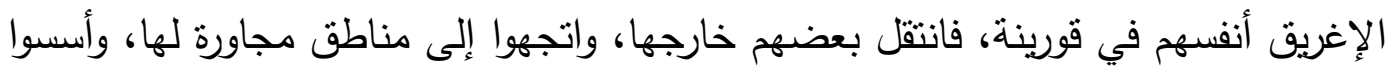

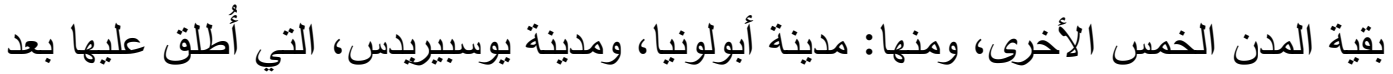
ذلك اسم برنيقي Berenice، ومن بعدها قام إخوة الملك الإغريقيَ بتأسيس مدينة

$\left.{ }^{1}\right)$ Kraeling, C. H. et als., Ptolemais City of the Libian Pentapolis, Chicago, 1962, pp. 2-3.

عبد العزيز طريح شرف: جغرفيا لبييا، الطبعة الثانية، الإنكندرية: منشأة المعارف، الو ام، ص ب؟ وما

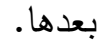

$\left(^{2}\right)$ Herodotus, The History, trans. Into English By G.C. Macaulay, 2 Vols. 3 edition, London, 1914, Vol.1, IV,156-158; Strabo, Geography, Translated by H.L. Jones. Loeb Classical Library 267, Cambridge, Harvard University Press, 1932, Vol. 8, 17.3.21, p. 203.

ميخائيل مكسي إسكندر: تاريخ المسيحية وآثارها، ص ع ؟ وما بعدها. لمزيد من التفاصيل حول أسباب

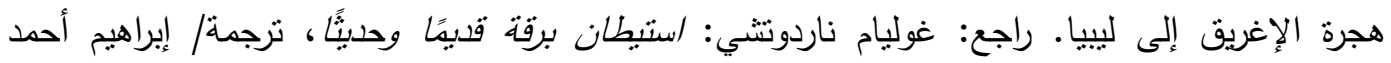

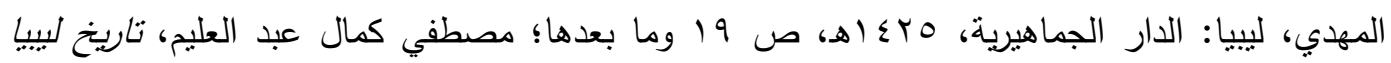

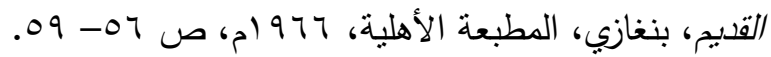


برقة Barca، ومن بعدها أسسوا مدينة توكرا Tochera، كما دعيث أيضًا طوكرة Tocra

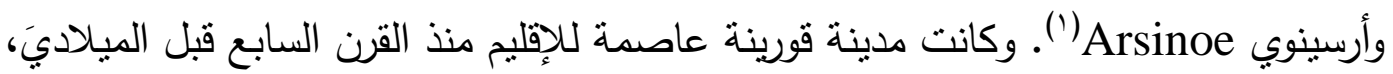

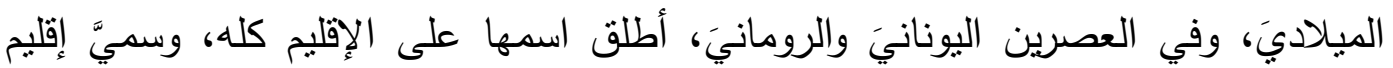

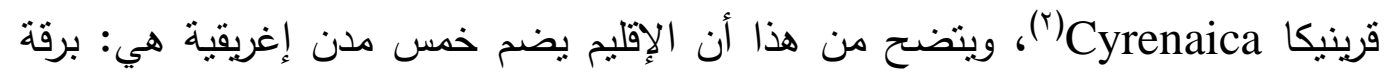
وقورينة وطوكرة وأبولونيا وبرنيقي التي هي بنغازي الحالية.

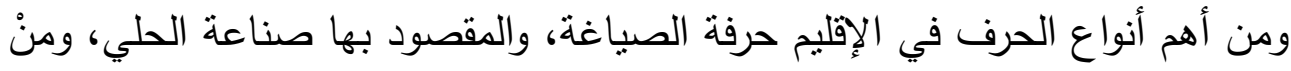

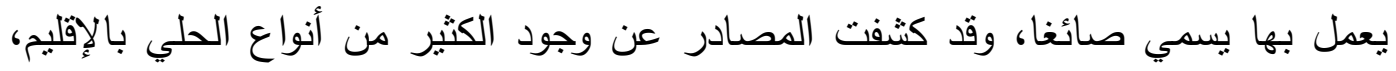
وهذا ما أكده سينسيوس في إحدى رسائله التي تحدث فيها عن فتاة تتنمي لعائلة ثرية كانت تعيش في مدينة طوكرة ترتني قطع الحلي المصنوع من الذهب والأحجار الكريمة، كما كانت

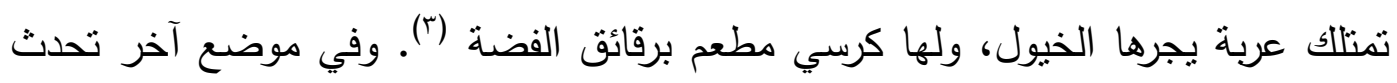

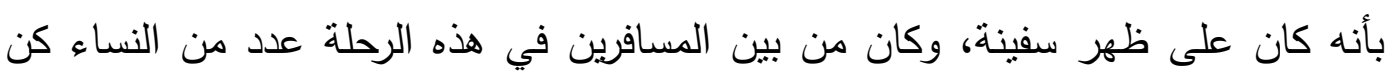
يملكن قلائد مصنوعة من المجوهرات (؛). ويتضح من هذا أن مدن إقليم قورينة ومنها مدينة توكرة كان يوجد بها حرفيون يعملون في صناعة أنواع الحلي مثل الأساور والخواتم والقلائد

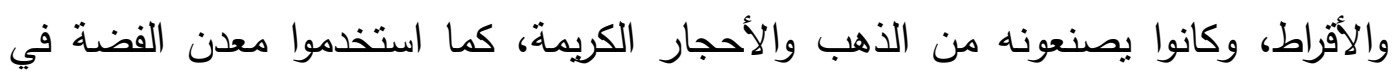

(1) Pliny, Natural History, Trans. by J. Bostock et als. London, 1855, Vol. 1, V.5, p. 396; Ammianus Marcellinus, The Roman History, With An English Trans. by J. Rolfe, 3 Vols. London, 1936-1939, Vol. 2, XXII.16.4.

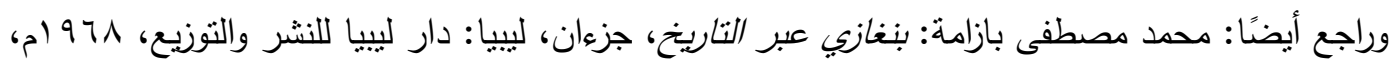

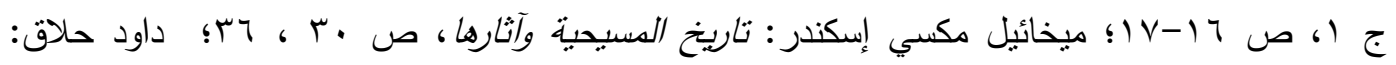

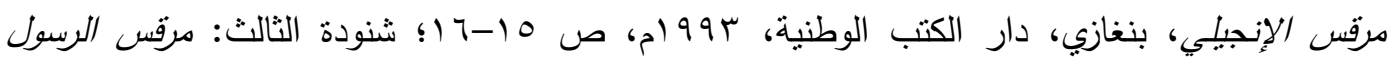

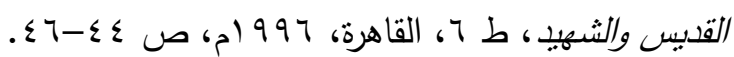

$\left(^{2}\right)$ Ammianus Marcellinus, The Roman History, Vol. 2, XXII.16.4; Strabo, Geography, Vol. 8, 17.3.20, pp. 199-201; Darby, W. (ed.), Dictionary Geographical, Historical and Statistical, $4^{\text {th }}$ edition, Philadelphia, 1845, p. 894; Darby, W. (ed.), A New Geographical Dictionary, Philadelphia, 1827, p. 795.

داود حلاق: مرقس الإنجيلي، ص 10. يجب أن نشير إلى أن بعضهم بعتقد أن هذه الددينة هي مدينة

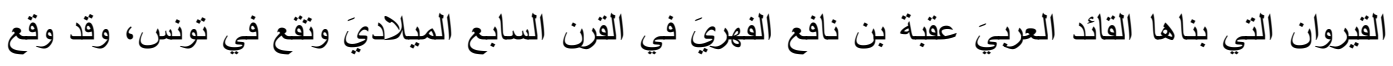

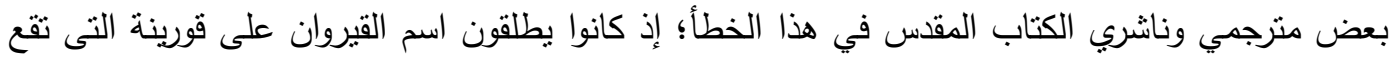

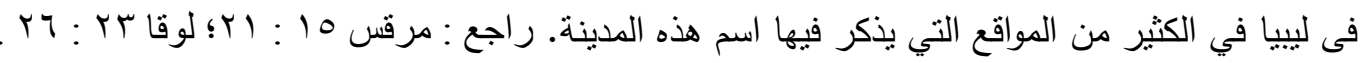
$\left(^{3}\right)$ Synesius of Cyrene, Letter to his Brother, dated in 402, in Essays and Hymns of Synesius of Cyrene, translated by A. Fitzgerald, London, 1930, No. 3.

$\left({ }^{4}\right)$ Synesius of Cyrene, Letter to his Brother, dated in 397, No. 4. 
صناعات أخرى مثل تطعيم بعض قطع الأثاث وكراسي عربات النقل التي نتقل الأثرياء من

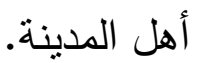

ونجد أيضًا حرفة الحدادة والذي يعمل بها يدعي حدادا، وكانت حرفته تقتضي أن

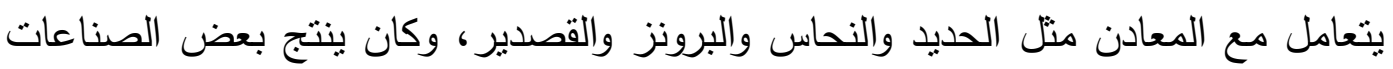

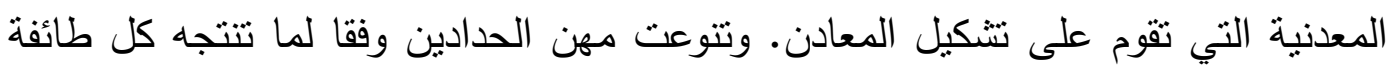

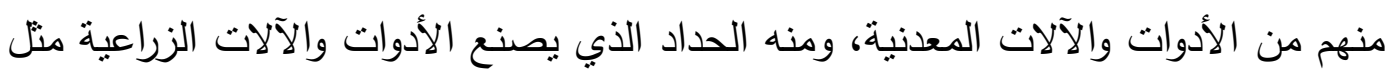

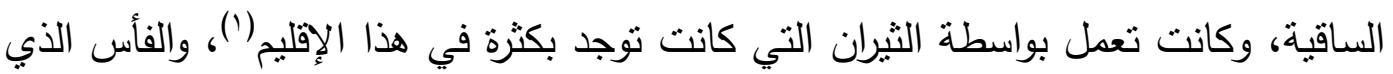

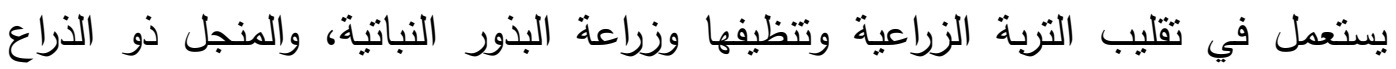
الحديدي الحاد الذي يستخدم في حصد المحاصيل الزراعية، ولا سيما محاصيل الحبوب متل

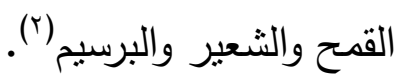

ومهنة الحداد المختص في صناعة الأدوات المعدنية الفلكية، ويتضح مهارة هؤلاء

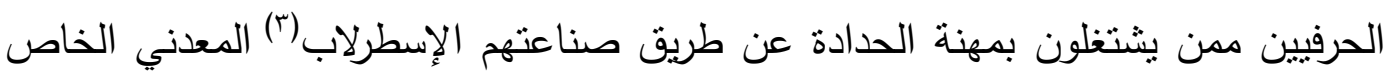

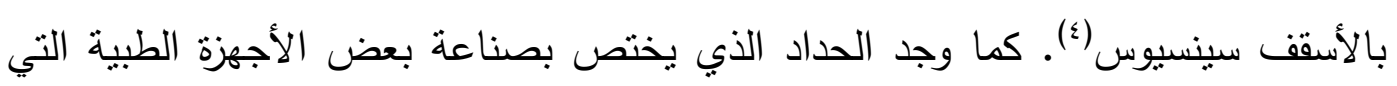
كانت مستعملة في هذا الزمان، ومنها صناعة جهاز هيدروسكوب Hydroscope

( ${ }^{1}$ ) Diodorus Siculus, Library of History, trans. by C.H. Oldfather, Loeb Classical

Library 303, Harvard University Press, 1935, Vol. 2, III.50.2, p. 241; Synesius of Cyrene, Letter to Olympius, dated in 408 A.D, No. 148.

$\left.{ }^{2}\right)$ Synesius of Cyrene, Letter to Olympius, No. 148.

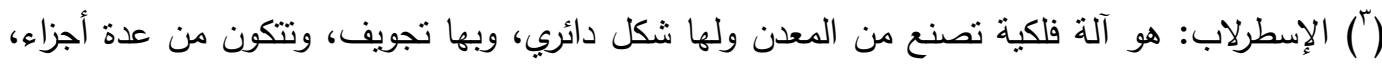

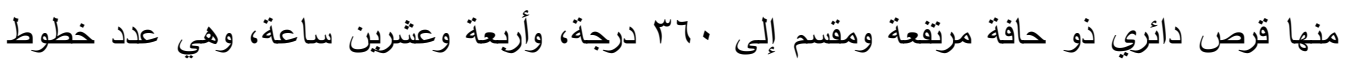

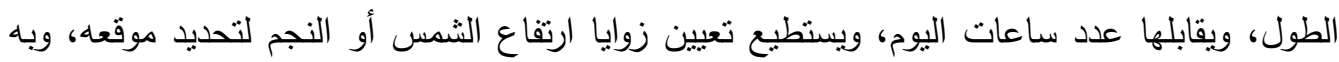

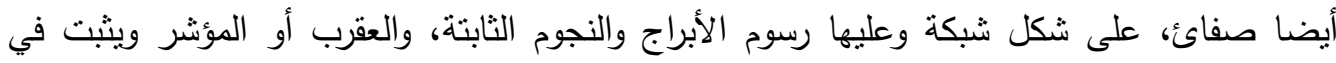

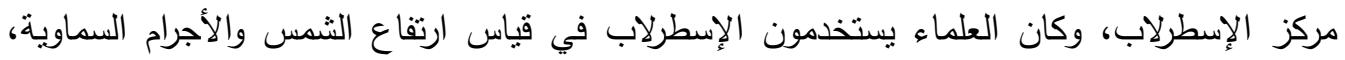

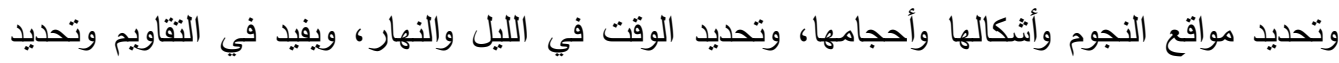

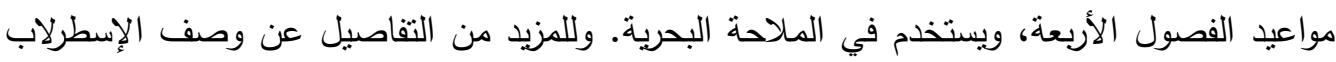
Janus, The Electronic Astrolabe, England, 2000, pp. 4-6.

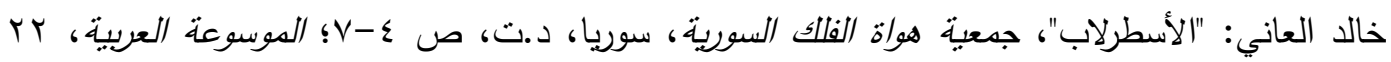

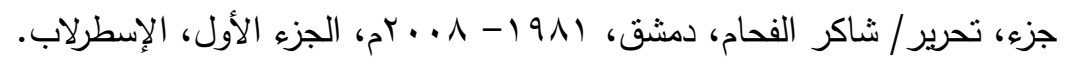

( ${ }^{4}$ ) Synesius of Cyrene, On an Astrolabe, in Essays and Hymns of Synesius of Cyrene, translated by A. Fitzgerald, London, 1930, Letter to his Brother, No. 3. (") هيدروسكوب: جاء وصف سينسيوس له بأنه جهاز تم صبه من النحاس، وينكون من أنبوبة أسطوانية 
وهناك الحداد الذي يقوم بصناعة الأدوات والآلات الحربية، التي كان أهل الإقليم يستخدمونها في مواجهة القبائل البربرية، التي كانت تعتدي على بلادهم من ناحية الجنوب حيث الصحراء الواسعة، التي يعيش فيها منل هذه القبائل الرحل(')، ومن تلك الأدوات السيوف الحديدية القصيرة التي كان ينتجها الإقليم، وكذلك البلطات التي لها أسلحة حديدية صلبة، والدروع، والسهام، والأقواس الحديدية التي لها رؤوس برونزية(r)، والدروع الحديدية، والهراوات التي تغطي بصفائح مصنوعة من الحديد، وكذلك الرماح|(') وحقيقة كانت هذه

على شكل المزمار، ولها قمة على نفس المسار وخط المحيط، ومعه قطعة علي شكل القمع، تعمل

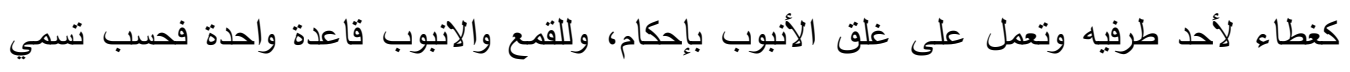

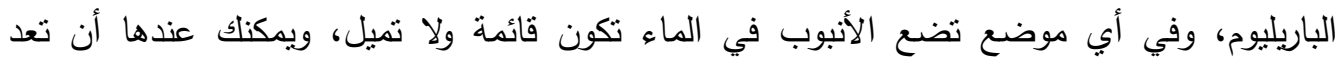
الأطراف العلوية بسهولة. ويعتقد العلماء أن هذا الوصف يعد أحد أنثال جهاز الساعة المائية التي كان يستخدمها الناس قديما لقياس الوقت، أو أنه مقياس لمنسوب الماء. وقد وصفه أحد العلماء بأنه عبارة

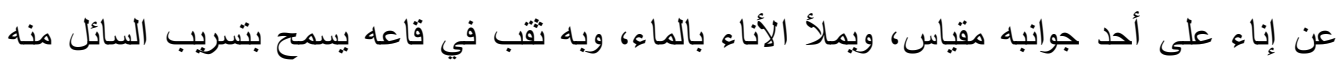

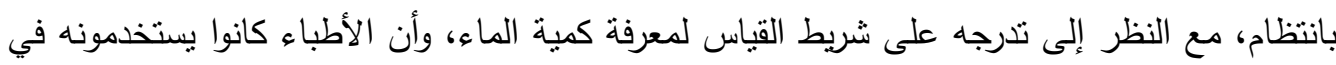
الطب، في قياس سرعة ضربات القلب، أو قياس كمية الدواء السائل الذي يتتاوله المريض.

Synesius of Cyrene, Letter to the Philosopher, dated in 402 A.D, No. 15; Deakin, M., "Hypatia and Her Mathematics", The American Mathematical Monthly 101/3 (March 1994), p. 241.

(') أفاضت مصادر المؤرخين القدامى في الحديث عن هذه القبائل ومسمياتها وأعراقها، ومنها المؤرخ هيرودوت الذي أورد الكثير منهم الناسمونيون، أي عباد أمون، ويعيشون في المنطقة الصحراوية ما بين الصنات

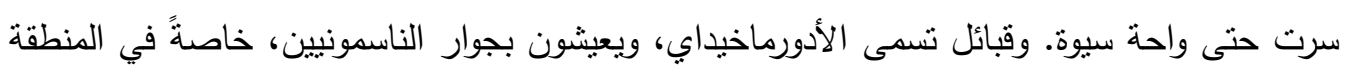
الواقعة في الصحراء الكبرى الممتدة في غرب مصر والمنطقة المعروفة باسم سيدي البراني. والمارمريد

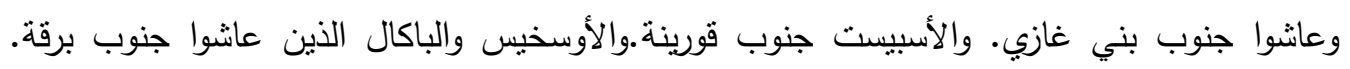

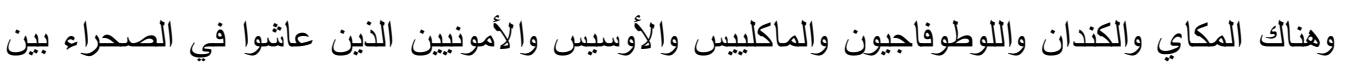
واحة سيوة وجنوب إقليم قورينة والكرامنيون والأطرانط والزوويس والجيزانت.

Herodotus, The History, Vol. 1, IV, pp. 168-199; Diodorus Siculus, Library of History, Vol. II, III. 50-55, pp. 240-259; Synesius of Cyrene, Letter to his brother, Dated in 407 A.D., Nos. 107-108.

( (ب) رؤوس السهام: كانت رؤوس السهام تصنع من الصوان ومن العظم، ثم صنعت بعد ذلك من البرونز ،

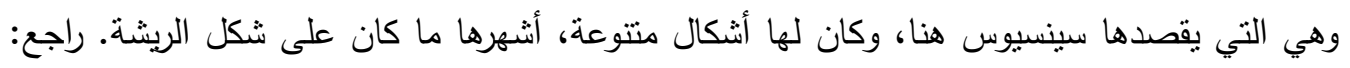

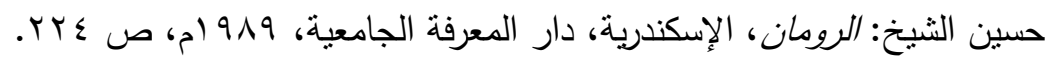

$\left(^{3}\right)$ Synesius of Cyrene, Letter to his brother, Dated in 407 A.D., Nos. 107-108;

Diodorus Siculus: Library of History, Vol. II, III. 49.4, pp. 239, 253; Herodotus, The History, Vol. 1, IV, pp. 180-193. 
الأدوات الحربية الخفيفة تتواجد بكثرة في مدن الإقليم ليدافع رجالها عن أراضيهح وممتلكاتهم ضد الهجمات الكثيرة التي يقوم بها القبائل البربرية ضدهم. كما وجدت هذه الأسلحة بكثرة في أيادي رجال ونساء البربر ('). كما صنعوا المنجنيق(ז)، وهو آلة حربية صنع هيكلها من الحديد، وكان لإقليم قورينة حاجة كبيرة له ليقاتل البربر أثناء مهاجمتهم لمدن إقليمه، واستخدمها قادة وزعماء الإقليم، ومنهم سينسيوس في هذه الهجمات (r). وكذلك وجدت مهنة النساج، وصانع الأغطية والبسط والستائر ، وصانع الملابس لأفراد الطبقات الغنية أو الفقيرة على السواء، في حين كان المميز منها كالمابس الأرجوانية(؟)

يجدر الإثارة بأن ثيودور الصقلي نتاول الرماح فحسب كسلاح من أسلحة اللبييين في أحد المواضع من

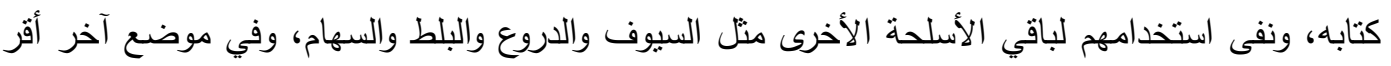

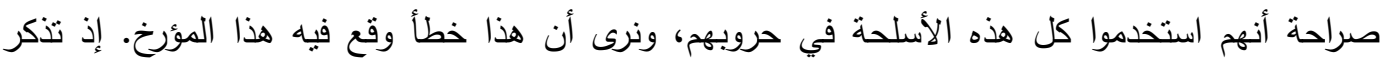
المصادر الأخرى، ولاسيما رسائل سينسيوس أنهم عرفوا السيوف والدروع والسهام والخوذات التي يرتندونها فوق رؤوسهم لحمايتها من ضربات السيوف. كما أنثار هيرودوت أنهم كانوا يستخدمون نوعا من العحلات الحربية في حروبهر وعرفوا الدروع •

( $\left.{ }^{1}\right)$ Heroduts, The History, Vol. 1, IV, pp. 175, 199; Synesius of Cyrene, Letter to his brother, Dated in 407 A.D., Nos. 107-108.

(r) المنجنيق : هو آلة حربية كانت تستخدم لقذف الحجارة والنار الأغريقية وكل ما يمكن قذفه من أجسام في الحروب داخل المدن بواسطة ذراع فيه كفة يتحرر تحت ضغط شديد، ويتحرك فوق عجلات، وكان من أهم أسلحة الحرب عند اليونان والرومان والعرب في العصور الوسطي. ويذكر أن سينسيوس تعلم

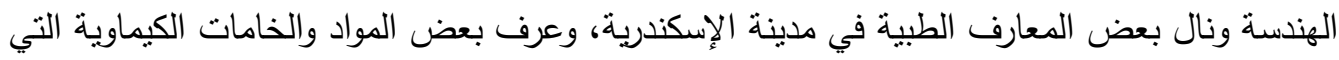

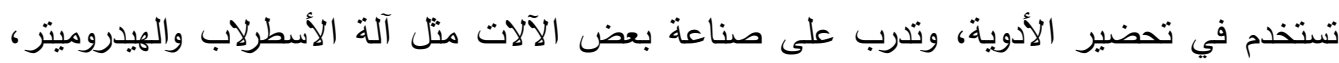
لذلك ليس غريبا عليه أن يصنع منجنيقا حربيا على مستوي عال من الدقة والإتقان، ويكون على معرفة الدية ببعض المواد الحارقة التي توضع في المنجنيق، وخاصة أنه في حاجة ماسة له ليقاتل البربر أثناء

$$
\text { مهاجمتهم لإقليمه. راجع : }
$$

Crawford, Synesius the Hellene, pp. 153, 155; Alice Gardner, Synesius of Cyrene, pp. 18, 58.

ستنفن رنسيمان: الحضارة البيزنطية، ترجمة/ عبد العزيز توفيق جاويد، الهيئة المصرية العامة للكتاب،

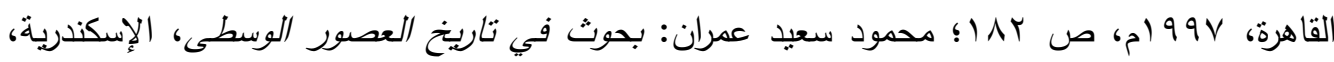

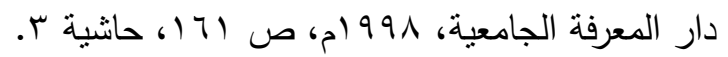

$\left(^{3}\right)$ Synesius of Cyrene, Letter to Olympius, Dated in 405 A.D., No. 133.

(أ) الملابس الأرجوانية: هي الملابس المصنوعة من الحرير، وكان هذا الحرير مصدره بلاد الصين فيستورد وينقل على يد التجار الفرس إلى بيزنطة والغرب الأوروبيَ. أما عن لونه الأرجوانيَ فيرجع 
مختصًا بأفراد الطبقات الثرية والملابس الحريرية والكتانية، وكذلك صناعة الملابس الجلدية والصوفية المصنوعة من جلود وأصواف الأغنام، حيث كانت تكثر الأغنام في الإقليم(')،

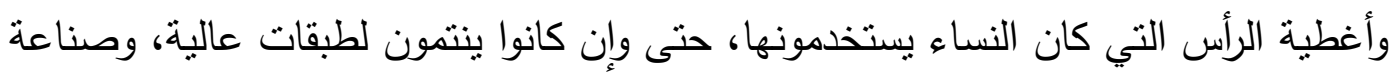

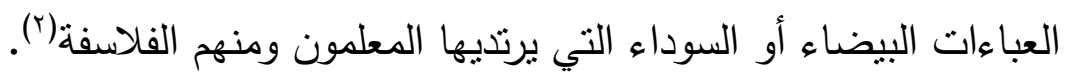

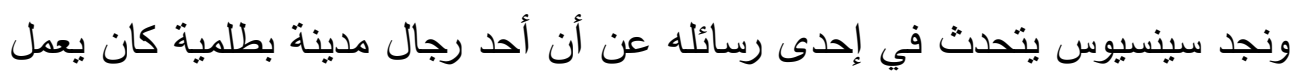

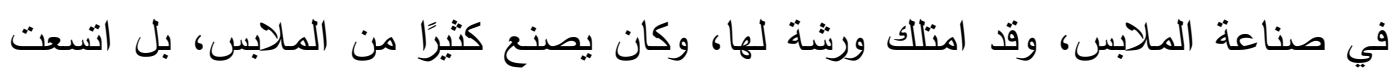

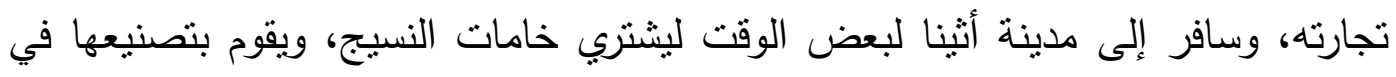

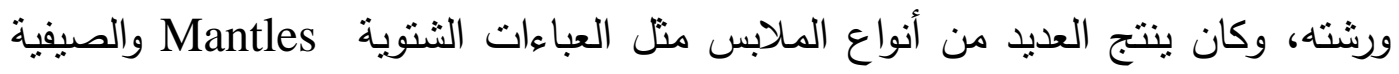
Robes، وغيرها من الملابس الأخرى الخفيفة الفاخرة عالية الجودة والصنع الأني تلائم

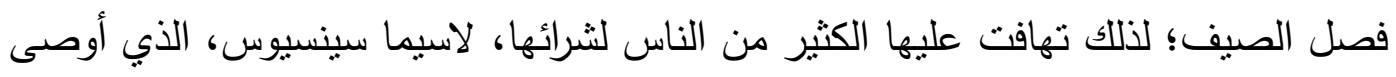

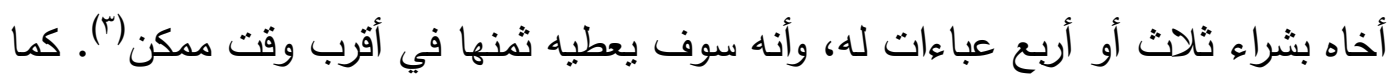

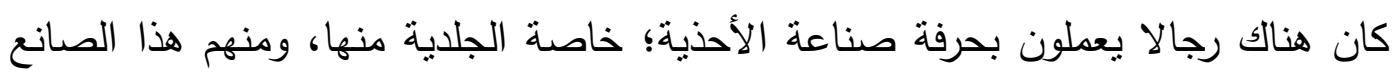
الذي كان يقوم بتصنيعها وبيعها للناس، وكان سينسيوس القوريني يشتري منه حاجنه من الإنه

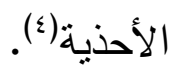

ويدخل ضمن عمليات الصناعة عملية أخرى قام بها بعض سكان المدينة، وهي

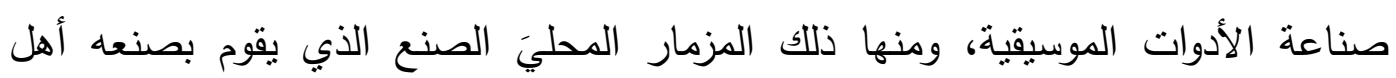

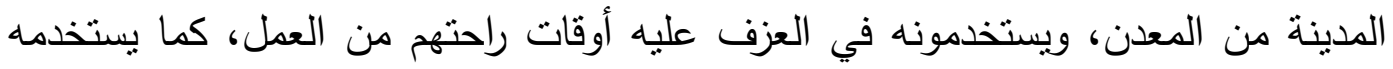

الفضل فيه لأهل مدينة صور الذين قاموا بصبغه باللون الأحمر الأرجواني بعد استخراجه من محاريات

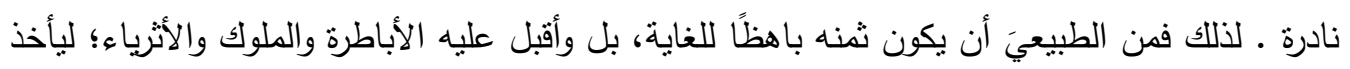

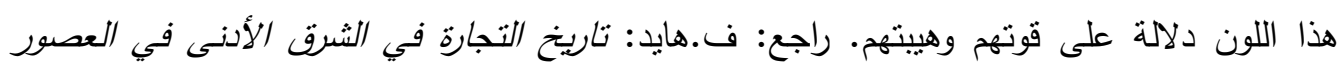

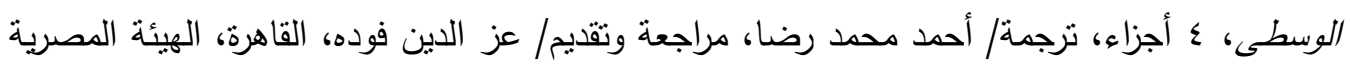

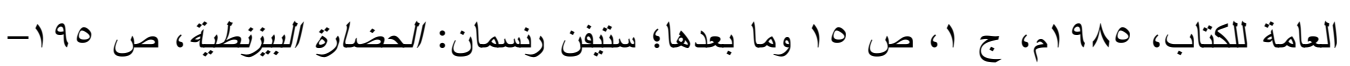
$.19 \mathrm{~V}$

( $\left.{ }^{1}\right)$ Diodorus Siculus: Library of History, Vol. II, III, 49.3, p. 239; Herodotus, The History, Vol. 1, IV, 189-193; Synesius of Cyrene, Letter to Olympius, No. 148

${ }^{(2)}$ Synesius of Cyrene, Letter to his Brother, Nos. 3-4; Letter to the philosopher, dated in 404, No. 154.

(3) Synesius of Cyrene, Letter to his Brother, dated in 402 A.D., No. 52.

$\left({ }^{4}\right)$ Ibid. 
الرعاة في نوجيه رعيتهم، وأثنار سينسيوس إلى أن أنغام المزمار كانت نطرب الفلاحين والطبقات العاملة (1).

ويرتبط بهذه المهن عدد من المهن الفنبة التي وجدت في المدينة، ولا سيما أن

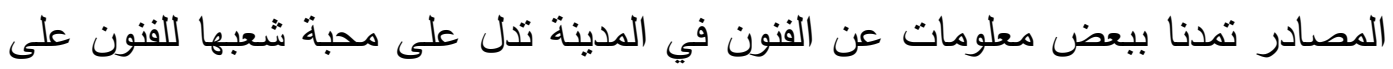
اختلاف أنواعها، ومنها الموسيقى والعزف والتمثيل والغناء، فهم يجيدون العزف على القينارة،

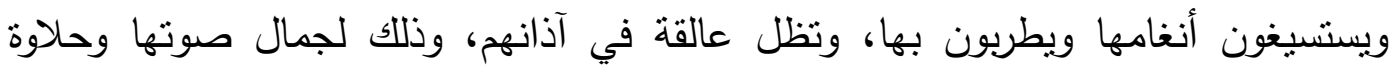

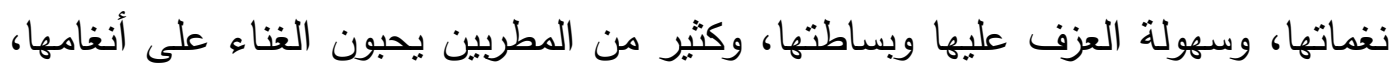
وكانت موضوعاتها الغنائية بعيدة عن الموضوعات العاطفية، ومنها مدح الكبش القوي الذي

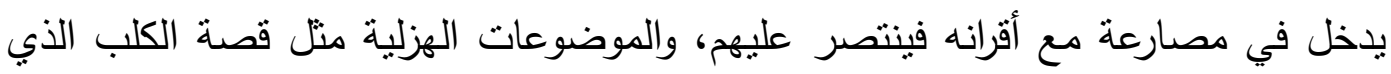

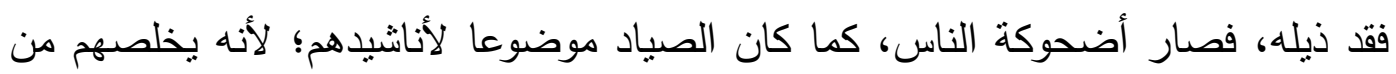

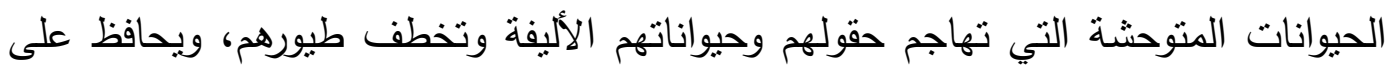

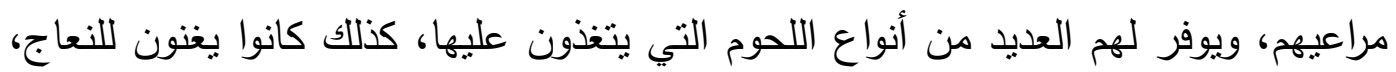

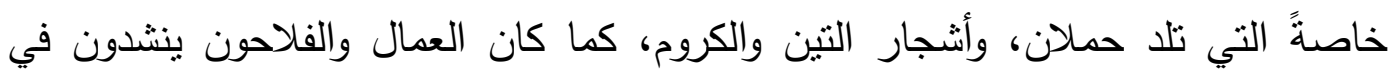
مواسم الحصاد، وأثناء عملهم في جني محاصيل الفاكهة والغلال، بالإضافة إلى ذلك تجدار تلهم يعرفون الإنشاد الديني، وفيه يتوسلون إلى الله كي يبارك في مدينتهم ورجالهم وأعمالهم

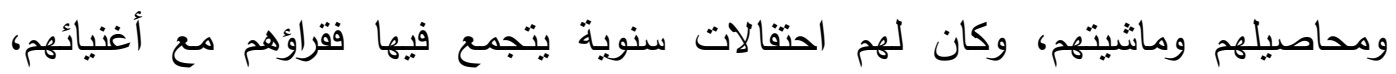
ويستمتعون بالرقصات الثعبية، وبالأغاني الجميلة، والألعاب والمهرجين والفنانين الذين لهنين يقومون بعرض بعض القصص الفنية المستوحاة من الإلياذة والأوديسة وبعض الأعمال الهزلية(r). وإن كان هذا ما ينعلق بفنون الطبقات الشعبية والعامة في المدينة من أغاني وأناشيد

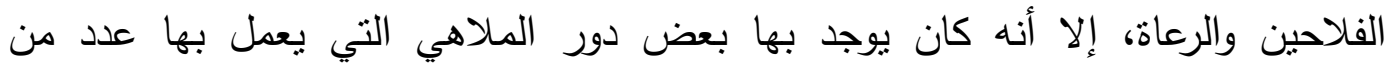

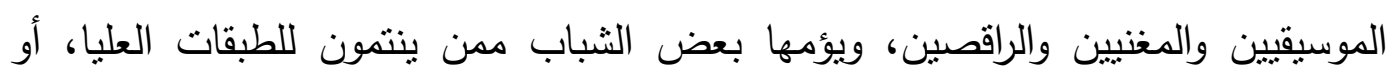
الثباب المحب للملذات، حيث كان يوجد بها الموسيقى الصاخبة والراقصين المنحرفين والمغنين، الذين يثيرون أذان سامعيهم بكلمات الأغاني المبنذلة، وتقام فيها الخمور التي لئي

( $\left.{ }^{1}\right)$ Synesius of Cyrene, Letter to Olympius, No. 148.

$\left({ }^{2}\right)$ Ibid. 
تذهب العقل ('). وكان بعض النساء يقومن بأدوار فنية في مسارح المدينة، وهن في عمر الثباب، ثم يعتزلن عملهن هذا عندما يتقدم بهن العمر، وتظهر عليهن ملامح الثيخوخة(r). ومن أنواع الحرف الأخرى التي عرفت في الإقليم حرفة النجارة، وهذه الحرفة تعتمد على الأخشاب اعتمادًا كبيرًا، وقد جاء في العديد من المصادر التاريخية أخبار عن وجود غابات شجرية في الإقليم بكثثر من مدنه مثل مدينة برنيقي التي كان بحاط بها غطاء نباتي كثيف وبساتين وحدائق متسعة(؟)، ومدينة بطلمية التي وجد بها سهل مارتل الغني بأشجاره الغابية(£)، ومدينة قورينة التي كانت الغابات تتنشر في جنوبها وعلى أطرافها(ه)، فقد كان يوجد غابات شجرية كثيرة بهذا الإقليم، وبهذه الغابات كثير من الأثجار منت أثجار البلوط الذي ينتشر في كل مدن الإقليم، والسرو الذي يوجد في مدينة قورينة، وشجر الأرز

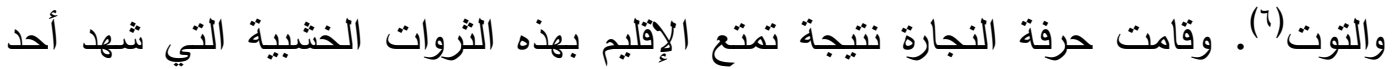
المؤرخين القدامى على جودة أخشابها(). فصنع منها الأسرة والكراسي الخشبية، كما استخدمت في صناعة العربات التي تجرها الخيول ومجاديف السفن، ومقابض بعض الآلات الحادة مثل السكاكين والخناجر، كما استعملت في أعمال التطعيم والزخرفة(^). ومن الصناعات المهمة أيضًا في الإقليم، صناعة السفن، وقد كانت الحاجة كبيرة إلى منل هذه الصناعة، ويرجع ذلك لوجود عدد من الموانيء بالإقليم، ومنها موانيء أبولونيا وبرنيقي وطوكرة وبطلمية؛ بسبب امتداد مدن الإقليم بالقرب من ساحل البحر المتوسط ، فلجأ سكانها؛ إلى هذه الموانيء لنقل منتجاتهم وتصديرها إلى البلاد والجزر الواقعة في دائرة

(1) Synesius of Cyrene, Letter to his Brother, dated in 402 A. D. No. 32.

$\left.{ }^{2}\right)$ Synesius of Cyrene, Letter to his Brother, dated in 402 A. D. No. 3.

( $\left.{ }^{3}\right)$ Ptolmee, Geography, trans. and ed. by E.L. Stevenson, Introdaction by J. Fischer, New York, 1932, IV; Pliny the Elder, The Natural History, Vol. 1, V.1, 5, pp. 376, 396-397; Theophrastus, Enquiry into Plants, Vol. 1, IV, 3.2, p. 305.

$\left({ }^{4}\right)$ Synesius of Cyrene, Letter to his Brother, dated in 407 , No. 122.

$\left({ }^{5}\right)$ Theophrastus, Enquiry into Plants, Vol. 1, IV, 3.1, p. 303; Synesius of Cyrene, Letter to Olympius, No. 148.

$\left({ }^{6}\right)$ Theophrastus, Enquiry into Plants, Vol. 1, IV, 3.1, 3, pp. 303, 305; Diodorus Siculus: Library of History, Vol. II, III, 50:1, p. 239; Synesius of Cyrene, Letter to Olympius, No. 148.

${ }^{7}$ ) Theophrastus, Enquiry into Plants, Vol. 1, IV, 3.4, p. 306.

( $\left.{ }^{8}\right)$ Theophrastus, Enquiry into Plants, Vol. 1, IV, 3.4, p. 307; Herodotus, The History, Vol.1, IV, pp. 180, 189, 193; Synesius of Cyrene, Letter to his Brother, dated in 402 A. D. No. 3; Letter to his brother, Dated in 413 A. D., No. 132 . 
البحر، مثل الإسكندرية وكريت وقبرص والساحل السوري، كما كان الكثير من أهلها يتتقلون عن طريق البحر، ولا سيما التجار والمسافرين للاراسة وتلقي العلم، والباحثين عن العمل، ولاسيما المتجهين منهم إلى الإسكندرية('). وقد اعتمدت هذه الصناعة على الخشب المتوفر بكثرة في غابات الإقليم.

وكان بعض الرجال بالإقليم يعملون في مهنة الملاحة البحرية، ويسافرون بحرًا إلى

سواحل البحر المنتسط وجزائره، وأثنار سينسيوس في إحدى رسائله إلى أعمال طاقم إحدى السفن، ووصف بعض أجزائها، فمن يقوم بها هو رئيس السفينة أو قائدها Shipmaster، وطاقم الملاحين Sailors، وكانت هذه السفن تدار بالمجاديف Oars، ولها أشرعة Sails، وتتاول الصفات التي يجب أن تتوفر في الذين يعملون في هذه المهنة، وتتلخص في أنه على ربان السفينة أن يكون على معرفة بالطرق البحرية، واتجاه الرياح، وأوقات النوات؛ حتى لا يعرض سفينته للخطر، وأضاف مثال على عدم معرفة بعض الربابنة بهذه الثروط ومنه: ذلك الربان قليل المعرفة بالبحر الذي رافقه على سفينته طاقم مكون من اثتى عشر بحارا، وأبحر من الإسكندرية متجهاً إلى قورينة، ويحمل عليها نحو خمسين مسافرًا، ثلثهم من النساء، وبنتمون لمدن إقليم بنتابوليس، ومنهم اليهود(r) واليونانيون، وأهل البلاد الأصليين، واشتدت عليه الرياح في البحر، وتصادم بالصخور، وأدرك الناس الذين على متتها الخطر، وقاربت السفينة على الغرق(). ولم تذكر المصادر اسم ذلك الربان، ولعل الأمر راجع إلى ولى ولى ولى

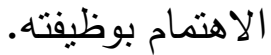

وإن كان سينسيوس يصف هنا بحارة هؤلاء السفينة وربانهم بعدم الخبرة؛ لأنهم لان يعرفون أوقات النوات أو الطرق البحربة، إلا أن ذللك لا ينسحب على البحارة كلهم، ففي رسالة أخرى نراه يقوم بإيجار سفينة لأحد أصدقائه، وبها مكوناتها جميعها، وعليها طاقهها

( $\left.{ }^{1}\right)$ Synesius of Cyrene, Letter to the philosopher, No. 4.

(†) يهود بنتابوليس: تذكر الموسوعة اليهودية أن يهود بنتابوليس قدموا إليها من مصر، ويرى بعض المؤرخين أن بطليموس الأول أتى بأعداد كبيرة منهم من فلسطين، وجعل منهم جنودًا للحامية اليونانية في برقة وغيرها من المدن، وسكنوا في مدن الإقليم ومنها قورينة وبطولمايس، وفي نحو عام 10 ق.م. كان لليهود وجود كبير في قورينة، وشكلوا نحو ربع سكانها، وكان لهم معابدهم ومجامعهم، ومارسوا

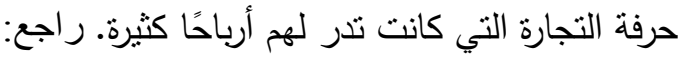

Morrison, W. D, The Jews under Roman Rule, London, 1890, pp.381382.

$\left(^{3}\right)$ Synesius of Cyrene, Letter to the philosopher, No. 4.

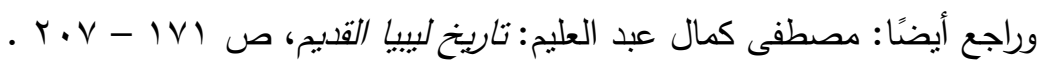


من البحارة، وهذه السفينة من النوع الذي يسمونه Vessel of the Carpathians

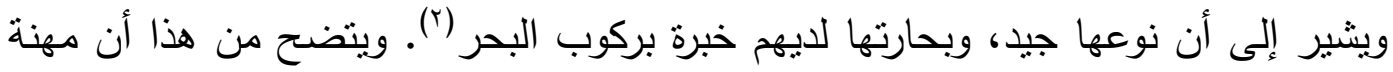
الملاحة البحرية كانت إحدى المهن المعروفة في إقليم قورينة.

وفيما يختص بحرفة الرعي في المدينة، بلاحظ نمو الحشائش بكثرة فيها؛ نتيجة وفرة

مياه الأمطار ووجود مياه الآبار وقنوات المياه العذبة الأخرى الناتجة عن روافد الأنهار التي ساعدت على وجود نشاط رعويَ في مدن الإقليم، لاسيما في الجزء الجنوبي منه (ז)، ونستخل على هذا من رسائل سينسيوس؛ إذ ورد بها وجود غابة نباتية، ومرعى كبير في وادي ميرتل الذي يقع في جنوب مدينة بطلمية، ويصفه بأنه منسع وعميق ومغطى بالأشجار

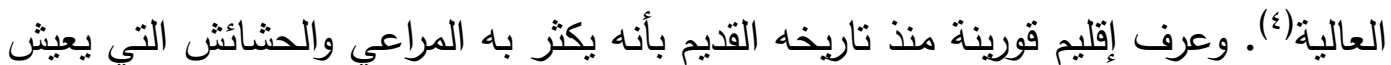

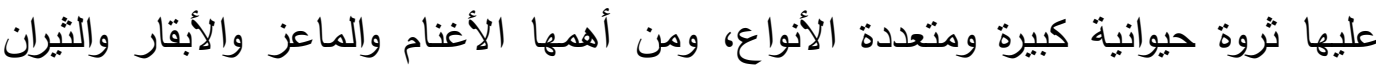
والجياد (ه).

وكان بعضُّ من سكان المدينة يعملون بهذه الحرفة، وبعضهم يزاولها بجانب الزراعة،

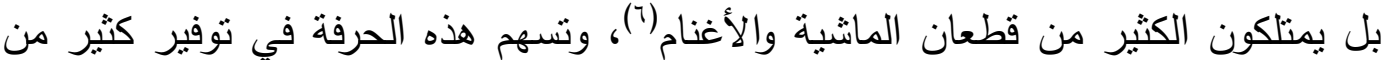

(') (') (') من أنواع السفن اليونانية القيمة التي استخدمها اليونان والرومان، وظلت حتى نهاية العصور

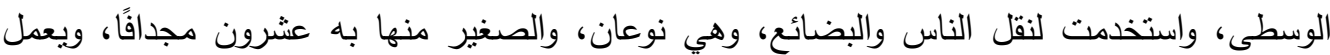

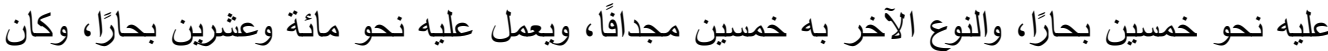

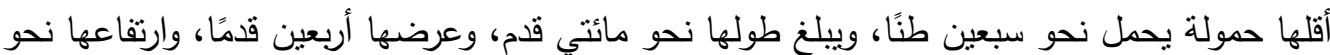

$$
\text { خمسة وأربعين قدمًا. وللمزيد راجع: }
$$

Saddington, D.B., Classes, The Evolution in the Roman Imperial Fleets; in A Companion to the Roman Army, ed. P. Erdcamb, Oxford, 2007, pp. 202-203; Nowak, R.J., "Archeological Evidence for Ship Eyes: An Analysis of their form and Function", Master of Art, Texas University, 2006, p. 52.

$\left({ }^{2}\right)$ Synesius of Cyrene, Letter to Friend, dated in 394 A. D., No. 41.

(3) Heroduts, The History, Vol. 1, IV, pp. 194-195.

$\left({ }^{4}\right)$ Synesius of Cyrene, Letter to his Brother, dated in 401 A. D. No. 104; Letter to his Brother, dated in 407 A.D. No. 122.

$\left({ }^{5}\right)$ Diodorus Siculus: Library of History, Vol. II, III, 49:3, p. 239. 50:2, p. 241; Herodotus, The History, Vol. 1, IV, pp. 186-189; Synesius of Cyrene, Letter to his Brother, dated in 396 A.D., No. 4; Letter to Olympius, dated in 408 A.D. No. 148.

(") اشتهر إقليم بنتابوليس ومدنه بإنتاج نوع من الأغنام يسمى البرقي نسبة إلى مدينة برقة التي تقع داخل

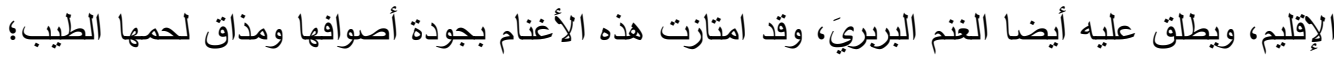
إذ إنها تتخذى على المراعي الطبيعية بالصحراء، وقدرتها على تحمل الظروف القاسية في الصحراء، الأهاء 
اللحوم التي يتخذى عليها السكان، لاسيما في الاحتفالات والأعياد، كما قامت عليها صناعات عديدة أخرى منل: صناعة الجبن والزبد بجانب الألبان الذين كانوا يأخذونها من الماعز، واعتمد أهل المدينة على هذه المنتجات في غذائهم بشكل كبير، كما كان نساء الفلاحين يقومون بتربية أنواع من الطيور الداجنة في منازلهم ، وهي عادة الفلاحين منذ القدم؛ حتى يومنا هذا؛ إذ لا يخلو بيت ريفيَ دنها، وتتسع بيوتهم لها ويوجد فيه أماكن مخصصة لها، ويتوافر الطعام الذي تتغذى عليه هذه الطيور من الثعير والذرة والخبز، ومنها الدجاج والروميَ' ('). وكان ثراء المدينة في الثروة الحيوانية من أحد أسباب تكرار هجوم البربر عليها؛ لأنهم كانوا يطمعون في ثرواتها الحيوانية بجانب منتجاتها الزراعية، وفي كل هجوم لهم على المدينة يقومون بسرقة الماثية والأغنام من الرعاة، كما كانوا يسرقون أعدادًا كبيرة من الجياد والجمال من الحقول وأيدي الفلاحين (r). وكان الكثير من سكان الإقليم يعملون بحرفة الصيد، وعرفوا نوعين من أنواع الصيد هما: صيد بريَ وهو الذي اشتهر به سكان الإقليم، لاسيما بطلمية وطوكرة وبرقة، وأشنار إليها سينسيوس في الكثير من رسائله التي تقيد بوجود حرفة الصبد في المدينة وبشكل كبير، بل أن حيوانات الصيد هذه كانت نشكل طعامًا رئيسًا لهم، ويرجع السبب في ذلك لوجود المراعي الغنية بالحشائش التي كان يتغذى عليها الكثير من الحيوانات والطيور البرية منل: النعام والغزال والأرنب البريَ والطيور ، ليس هذا فحسب، بل وجدت بها الحيوانات البرية منل لهن الثعالب والفيلة والأسود والحمر الوحشية ذات القرون والأيائل والكباث البرية والغزلان، وذلك

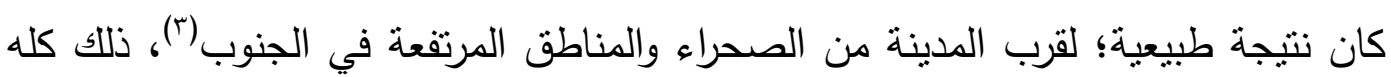

كما أنها ولا تزال إلى اليوم تشتهر بها. والرأس صغيرة ذات أنف مستقيم، والأذن شبه بندولية متوسطة،

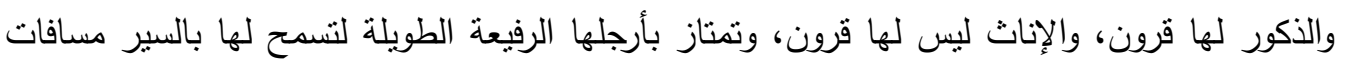

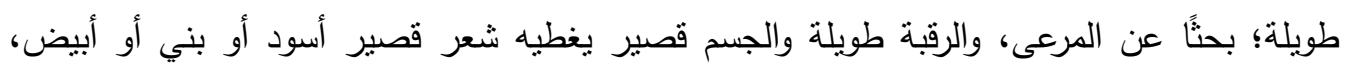

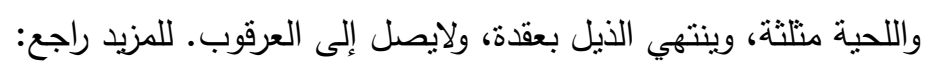

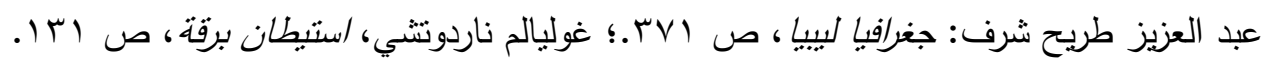

( ${ }^{1}$ ) Synesius of Cyrene, Letter to his Brother, dated in 396 A.D., No. 4; Letter to his Brother, No. 104; Letter to Olympius, No. 148.

$\left(^{2}\right)$ Synesius of Cyrene, Letter to his Brother, No. 104; Letter to Olympius, No. 148.

$\left({ }^{3}\right)$ Diodorus Siculus: Library of History, Vol. II, III, 50:2, p. 241. 53:5, p. 251; Herodotus, The History, Vol.1, IV, p. 191; Synesius of Cyrene, Letter to his 
جعل لحوم الحيوانات المستأنسة أساس المائدة عندهم، بل كان سينسيوس نفسه يمارس

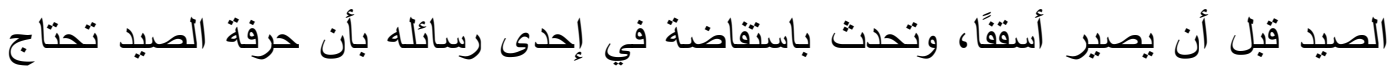

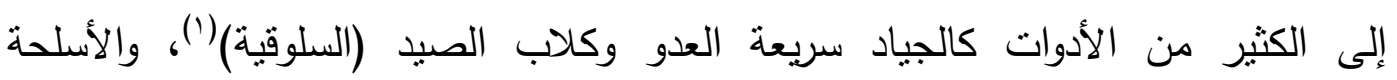

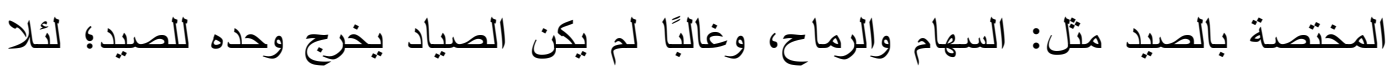
يتعرض لهجوم من وحوش البرية، وتتعرض حياته للخطر، بل كان برافقه بعض الرجال الآخرين. وعلى الرغم من أهمية هذه الحرفة والناتج عنها، فإن الكثير من سكان بطلمية يتجنبون تتاول لحوم حيوانات الصيد، ويعدونها لحومًا دنسة، غير أن سينسيوس كان يلان يرى أنها ليس طعامًا دنسًا طالما أنضجته النار (؟). وكنلك من أنواع الصيد، كان الصيد البحريَ، وقد أسهم موقع الإقليم وقرب البحر منه

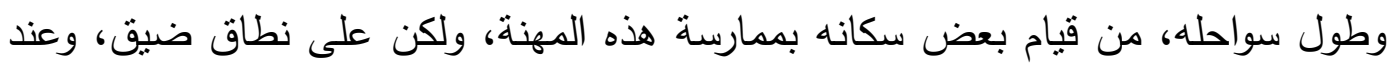
الضرورة فحسب، ويتضح ذلك في رسائل سينسيوس واثناراته إلى أنه في أثناء إحدى رحلاته

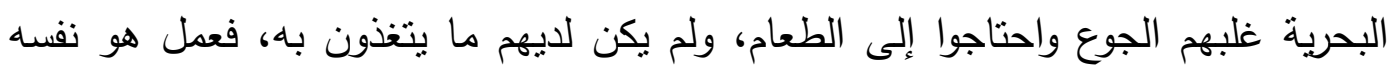

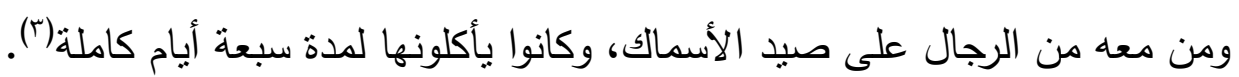
كما كان الكثير من أهل الإقليم يعطلون في عدد من الحرف المتعلقة بالصناعات

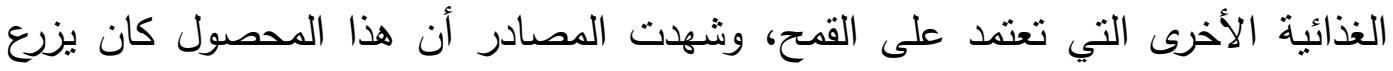
بكثرة في الإقليم؛ لأن أرضه سوداء وكثيفة، وتتتوع بها مصادر المياه واعتدال المناخ، وكل لفئل

Brother, dated in 396 A.D., No. 4; Letter to Olympius, dated in 408 A. D., No. 148.

(') الكلاب السلوقية: اشتهرت ليبيا والثمال الإفريقيَ حتي بلاد المغرب بوجود هذا النوع من الكلاب،

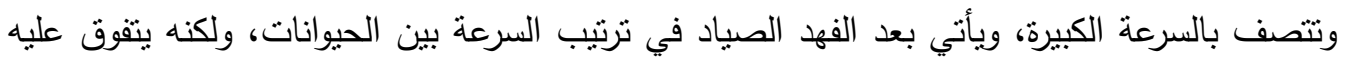

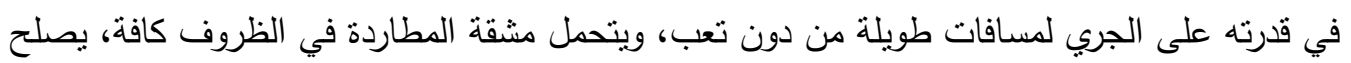

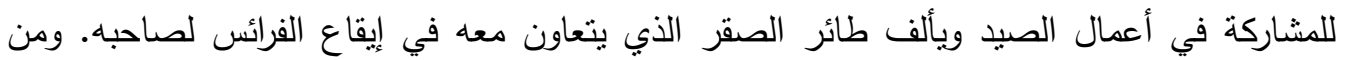
صفاته الجسمانية أنه نحيف وعالي البنية ومقوس الظهر وضامر البطن ومنخفض الصدر وطويل

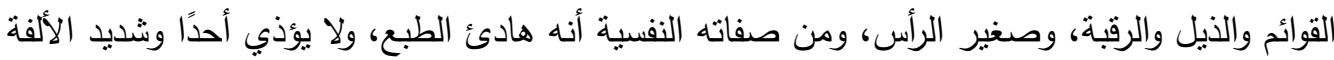

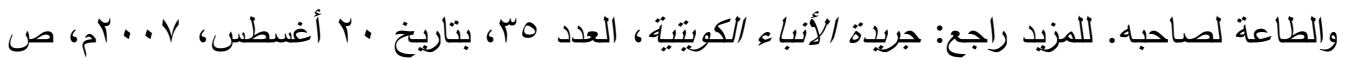
ro

( $\left.{ }^{2}\right)$ Synesius of Cyrene, Letter to Uranius, No. 40; Letter to his Brother, No. 105; Letter to Pylaemenese, No. 134; Letter to Olympius, No. 148.

$\left({ }^{3}\right)$ Synesius of Cyrene, Letter to the philosopher, No. 4. 
هذه الظروف الطبيعية تتاسب زراعة القمح'(). وحرفة طحن القمح اللزمة لصناعة الخبز والحلويات، وحرفة صناعة الحلوبات، حيث تحدثت رسائل سينسيوس القوريني عن هذه الحرف، وعددت أنواع الحلوبات التي كانوا يصنعونها من القمح مثل أنواع الكعلك والفطائر (؟). كما استخدموا الشعير في صناعة بعض أنواع الأغذية والمشروبات، حيث كان يزرع بكثرة عندهم(r)، ومن أهم الصناعات التي قامت عليه هنالك صناعة خبز الشعير بعد طحنه، وصنعوا منه كعك الثعير ، ونوع آخر من الحلويات يسمى barley-groats ، كان

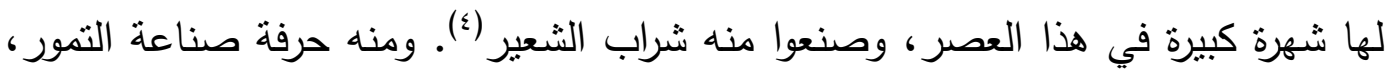
حيث تشهد المصادر أن إقليم قورينة كثر فيه زراعة نخيل البلح(ه). ومن الحرف الأخرى التي مارسها سكان الإقليم حرفة استخراج الزيوت، وكان الإقليم ومدنه ينتجون كميات كبيرة من الزيت المستخلص من ثمار الزيتون الذي زرع بكثافة في هذا الإقليم(†)، ووصف زيتها بأنه جيد، وله استخدامات كثيرة، فهو يدخل في الطعام، وبستخدم في الإنارة، كما تعتمد عليه الكنائس في طقوسها، ويعتمد عليه بعض الرياضبين في تدرببهم، ويعمل على جعل عضلاتهم لينة، كما بدخل في صناعة الدواء والعلاجات الصحية، وكان له شهرة كبيرة في الأسواق الداخلية والخارجية من حيث جودته وفائدته، ويتقوق على ما عداه في مكان ينتجه، حتي على ما ينتج منه في بلاد اليونان(').

( $\left.{ }^{1}\right)$ Diodorus Siculus: Library of History, Vol. II, III, 50:1, p. 239; Synesius of Cyrene, Letter to Olympius, No. 148.

$\left(^{2}\right)$ Synesius of Cyrene, Letter to Olympius, No.148; Letter to the philosopher, No. 4.

$\left({ }^{3}\right)$ Diodorus Siculus: Library of History, Vol. II, III, 73:7, p. 329; Synesius of Cyrene, Letter to Olympius, No. 148.

( $\left.{ }^{4}\right)$ Synesius of Cyrene, Letter to the philosopher, No.4.; Synesius of Cyrene, Letter to Olympius, No.148.

$\left(^{5}\right)$ Theophrastus, Enquiry into Plants, Vol. I: IV, 3:1, p. 303, 3:5, p. 307; Herodotus, The History, Vol.1, IV, p. 199.; Synesius of Cyrene, Letter to Olympius, No.148.

$\left({ }^{6}\right)$ Diodorus Siculus: Library of History, III, 50: 1, p. 239; Theophrastus, Enquiry into Plants, Vol. I: IV, 3:1, p. 303; Synesius of Cyrene, Letter to the Theophilus, Dated in 411 A. D., No. 67; Letter to his brother, Dated in 407, A. M., No.108; Letter to Pylaemenese, Dated in 406 A.D., No.134; Letter to Olympius, dated in 408 A. D., No.148; Letter to an unknown Correspondent, dated in 411 A. D., No.15.

( ${ }^{7}$ ) Synesius of Cyrene, Letter to Olympius, No. 148. 
ومنه حرفة صانع النبيذ، حيث صرحت المصادر بأن زراعة الكروم كانت منتشرة بكثرة في الإقليم(') ومنه حرفة استخراج ملح الطعام، وكان أهل الإقليم بستخرجونه من بن

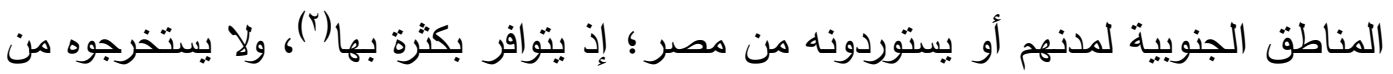
المناطق الساحلية؛ لأن بعضهم كانوا يخشون من أي منتج يخرج من البحر؛ لاعتقادهم الخاطئ بأن البحر لا يخرج منه شيء لله فائدة، وأن الأرض فقط هي التي يخرج منها طعامهم كله. كما عرفوا ملح النطرون الذي بستخدم في صناعة الصباغة، وأطلقوا عليه اسم ملح أمون(r)، وكان له الكثير من الاستخدامات، لاسيما في طهي الأطعمة؛ إذ يكسبها

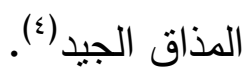

كذلك عرف الإقليم حرفة أخرى وهي النحال، الذي يقوم بجمع عسل النحل الأبيض، واشتهرت مدن الإقليم - لاسيما مدينة بطلمية - بإنتاج عسل النحل بكميات كبيرة، واعتمد عليه أهل المدينة بشكل واضح في غذائهم هذا من جانب. أما الجانب الآخر فكان يدخل ضدن المنتجات التي تقوم المدينة بتصديرها إلى الخارج، كما كانت تجارته رائجة محليًا أيضًا، وربما يرجع ذلك إلى اتساع مساحة بساتين الفاكهة والنباتات الزهرية في الإقليم، واهتمام الفلاحين بوضع مناحل العسل داخل هذه البساتين(؛).

( $\left.{ }^{1}\right)$ Theophrastus, Enquiry into Plants, Vol. I: IV, 3:1, p. 305; Diodorus Siculus: Library of History, Vol. II, III, 50: 1, p. 239.

$\left({ }^{2}\right)$ Diodorus Siculus: Library of History, Vol. II, III, 51, p 239; Herodotus, The History, Vol. I, IV, pp. 182-183.

وراجع: الفريد لوكاس: المواد والصناعات عند قدماء المصربين، ترجمة/ زكي إسكندر ومحمد زكريا غنيم،

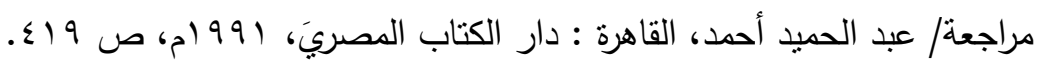

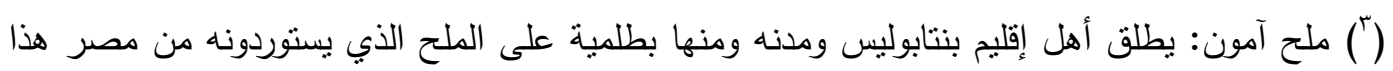

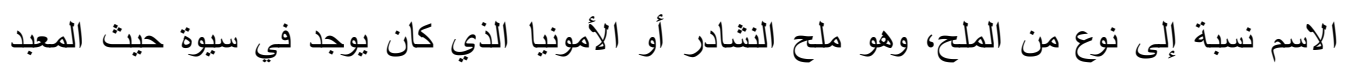
الثهير للإله أمون، وقد نسبت سيوة لهذا المعبود المصريَ القديم الذي اشتهرت عبادته في الدولة الحديثة، وفي عصر الإسكندر الأكبر أطلق على الواحة اسم واحة الإله آمون، ولعلهم أخذوا هذا الاسم منها؛ لقربها من الإقليم.

Boyd, L. M., "Ammonia, The Salt of Ammon", in Newspapers, Beaver County Times, Jun 13, 1995, p. 8.

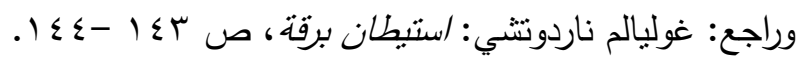

(') Synesius of Cyrene, Letter to Olympius, No. 148.

$\left({ }^{5}\right)$ Synesius of Cyrene, Letter to Olympius, No. 148. 
كما عرفت عندهم مهنة الطب والعلاج، وقام سينسيوس بيناء مشفى صغير في كي المدينة، واستقبل فيه المرضى، وكان يقدم لهم الخدمة والعلاج بالمجان، واستعان كثيرًا

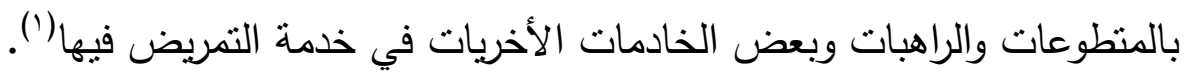
ومنه مهنة المكاري، الذي يعمل لاى أفراد الطبقات العليا في المجتمع ممن يمتلكون عربات تجرها البغال والجياد، وقد كان للأسقف سينسيوس عربة تجرها البغال، ولديه أحد المكاريين، يقودها له عند خروجه من منزله لاستقبال ضيوفه القادمين بحرا من الموانيء، أو

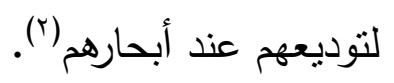

ونستتنج مما سبق في النشاط الصناعيَ والحرفي في إقليم قورينة وجود وفرة في المواد الخام التي تمتلكها المدينة، ومنها: مواد خام زراعية منل الفاكهة المتتوعة كالتفاح

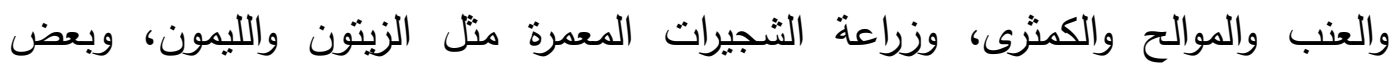
الحاصلات الأخرى منل الحبوب كالقمح والثعير وشجيرات ونباتات عشبية منل السلفيوم.

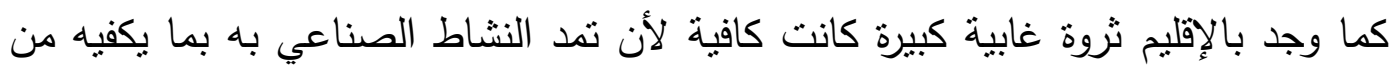

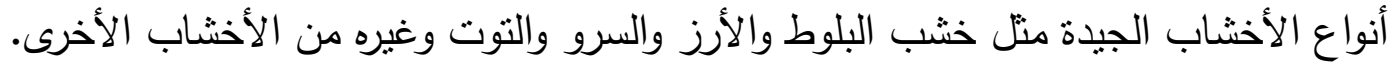

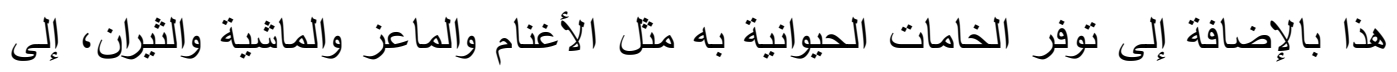

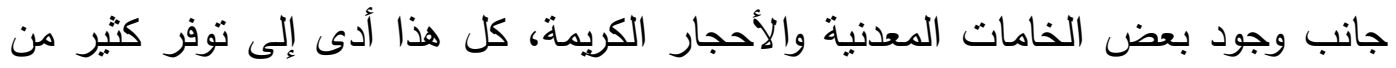

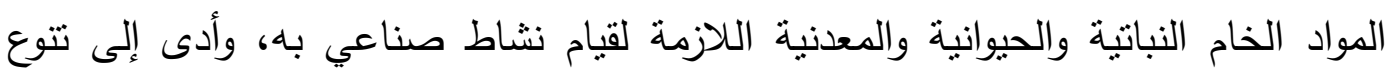

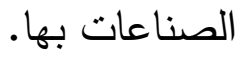

ومن أنواع المهن والصناعات التي وجدت في الإقليم مهنة الصياغة؛ وقد كانوا يستعملوا الذهب والفضة والأحجار الكريمة، التي دخلت في صناعة ولنة الحلي والزينة منل الأقراط والأساور والقلائد والخلاخيل، كما استخدموا هذه الخامات في تطعيم بعض قطع فئه

واتضح منه أنهم عرفوا حرفة الحدادة، وتتوعت مهن الحدادين وفقا لما ينتجه كل طائفة منهم من الأدوات والآلات المعدنية، ومنه الحداد الذي يصنع الأدوات والآلات

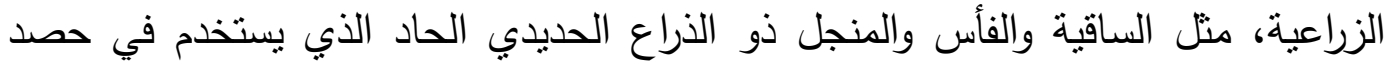
المحاصيل الزراعية. ومهنة الحداد المختص في صناعة الأدوات المعدنية الفلكية متل

(') مذكرات إيرين: ترجمة/ رودلف مرقس يني، مجلة مدارس الأحد، القاهرة، بيت مدارس الأحد، اب79 ام،

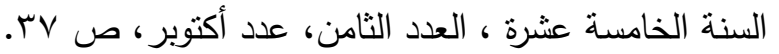
(2) Synesius of Cyrene, Letter to His Brother, dated in 359 A. D., No. 55. 
الإسطرلاب. كما وجد الحداد الذي يختص بصناعة بعض الأجهزة الطبية التي كانت مستعملة في هذا الزمان، ومنها صناعة جهاز هيدروسكوب. وهناك الحداد الذي يقوم بصناعة الأدوات والآلات الحربية مثل السيوف الحديدية القصيرة، وكذلك البلط التي لها أسلحة حديدية صلبة والدروع والسهام والأقواس الحديدية والدروع الحديدية والهراوات التي تغطي بصفائح مصنوعة من الحديد والرماح. كما صنعوا المنجنيق. وعرفوا حرفة صناعة المنسوجات والملابس، وصنعوا الملابس لأفراد الطبقات الغنية أو الفقيرة علي السواء مثل الملابس الأرجوانية والعباءات الصيفية والثتوية وقبعات الرأس والملابس الجلدية والصوفية. كما وجد عندهم حرفيين لصناعة الأحذية الجلدية الممتازة. واتضح منه أيضا أنهم عرفوا صناعة الأدوات الموسيقية المتنوعة منل الناي والمزمار والقيثارة، وأنه كان يوجد من بين القورنائيين عدد من أهلها عملوا بالحرف الموسيقية مثل المغنيين والراقصين والراقصات والمهرجين الذين عملوا بالتمثيل على المسارح والعازفين على الآلات الموسيقية هذه. كما عرف الإقليم مهنة النجارة التي اعتمدت على الأخثاب الجيدة والمتتوعة المتوفرة في غاباته في صناعات عديدة منل الأسرة والكراسي الخثبية ومجاديف السفن، كما استخدم في صناعة العربات التي تجرها الخيول ومجاديف السفن، ومقابض بعض الآلات الحادة مثل السكاكين والخناجر ، كما استعمل في أعمال التطعيم والزخرفة. كما تبين أن صناعة السفن كانت من الصناعات المعروفة بالإقليم، حيث كانت الحاجة كبيرة إلبها في نقل البضائع والأفراد عن طريق البحر، وقد اعتمدت هذه الصناعة على الخشب المتوفر بكثرة في غابات الإقليم. وارتبط بهذه الصناعة حرفة أخرى هي الملاحة البحرية، حيث عمل بعضهم بحارة وربابنة للسفن وعمال انقاذ بحري. كما اتضح منه أن حرفة الرعي كانت من الحرف المهمة في الإقليم، حيث كثرت الغابات والحشائش به، ومن أهم حيواناتها: الماشية والأغنام والماعز والثيران والماثية والجياد. هذا إلى جانب معرفة أهل المدينة بحرفة الصيد بنوعيه البريَ والبحرييَ، حيوانات الصيد هذه كانت تشكل طعامًا رئيسًا لهم، واعتمد الصيد البحري على أنواع الأسماك والقشربات، أما الصيد البري فكان معروفا هناك ومنتشرا نتيجة انتشار المراعي والغابات، واتضح منه أنه من أهم حيوانات الصيد عندهم النعام والغزال والأرنب البريَ والطيور ليس هذا فحسب، بل وجدت بها الحيوانات البرية منت الثعالب والفيلة والأسود والحمر الوحشية 
ذات القرون والأيائل والكباش البرية والغزلان. وأنهم كانوا يستخدمون الجياد والكلاب السلوقية

$$
\text { والحراب كأدوات في الصيد البري. }
$$

كما كان الكثير من أهل الإقليم يعملون في عدد من الحرف المتعلقة بالصناعات

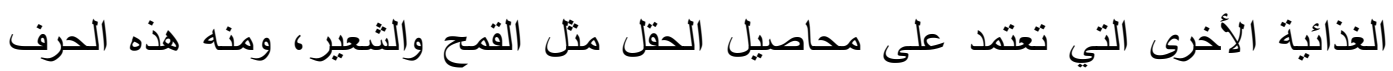

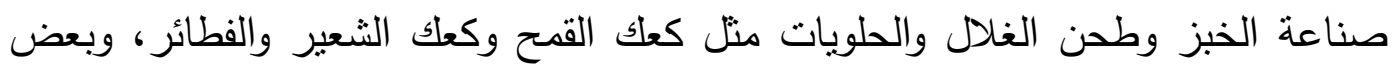

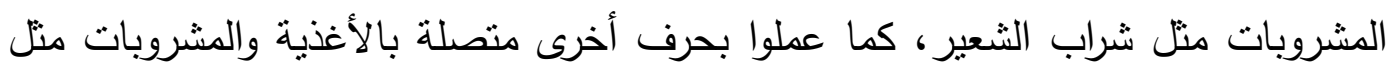

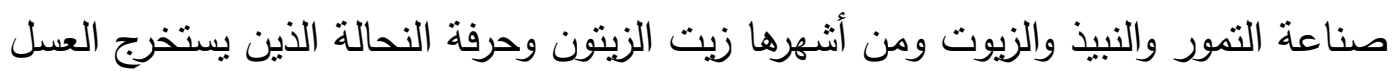

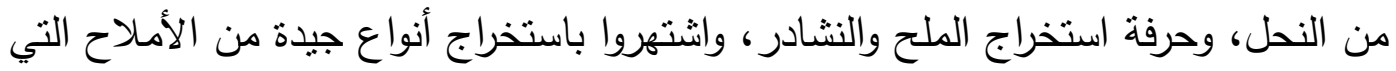
كان له شهرة كبيرة في العصر البيزنطي. كما عرف الإقليم صناعة الأدوية، ومارس بعضا من رجاله مهنة الطب والتمريض، وعمل البعض في هذه المهنة عن طريق النطوع، فوجد منطوعين ومتطوعات يعملون بمهنة

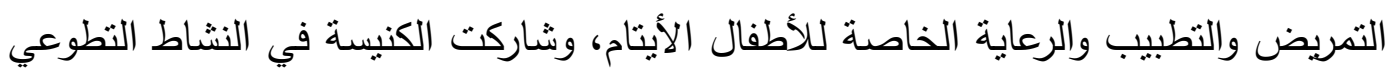
هذا بما أقامته من دور رعاية ملحقة بها. 


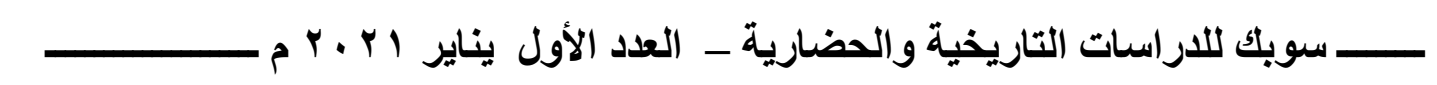

\section{قائمة المصادر والمراجع}

أولا المصادر الأجنبية:

- Ammianus Marcellinus, The Roman History, With An English Trans. by J. Rolfe, 3 Vols. London, 1936-1939.

- Diodorus Siculus: Library of History, trans. by C.H. Oldfather, Loeb Classical Library 303, Harvard University Press, 1935.

- Herodotus, The History, trans. Into English by G.C. Macaulay, 2 Vols. 3 edition, London, 1914.

- Pliny, Natural History, Trans. by J. Bostock et als. London, 1855.

- Ptolmee, Geography, trans. and ed. by E.L. Stevenson, Introduction by J. Fischer, New York, 1932.

- Strabo, Geography, Translated by H. L. Jones, Loeb Classical Library 267, Cambridge, Harvard University Press, 1932.

- Synesius of Cyrene, Letters, in Synesius of Cyrene, Essays and Hymns, translated by A. Fitzgerald, London, 1930.

- Synesius of Cyrene, On an Astrolabe, in Synesius of Cyrene, Essays and Hymns, translated by A. Fitzgerald, London, 1930.
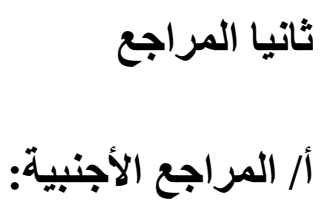

- Bregman, J., Synesius of Cyrene Philosopher and Bishop, California, 1982.

- Crawford, W.S., Synesius the Hellene, London, 1901.

- Darby, W. (ed.), A New Geographical Dictionary, Philadelphia, 1827.

- Darby, W. (ed.), Dictionary Geographical, Historical and Statistical, Fourth edition, Philadelphia, 1845. 
- Boyd, L.M., "Ammonia, The Salt of Ammon", in Newspapers, Beaver County Times, Jun 13, 1995.

- Deakin, M., "Hypatia and Her Mathematics", The American Mathematical Monthly 101/3 (March 1994).

- Gardner, A., Synesius of Cyrene, London, 1886.

- Morrison, W. D, The Jews under Roman Rule, London, 1890.

- Janus, The Electronic Astrolabe, England, 2000.

- Kraeling, C, H. et als., Ptolemais City of the Libian Pentapolis, Chicago, 1962.

- Nicol, J. C., Senysius of Cyrene: His Life and Writings, Cambridge, 1887.

- Nowak, R. J., "Archeological Evidence for Ship Eyes: An Analysis of their form and Function", Master of Art, Texas University, 2006.

- Saddington, D.B., "Classes, The Evolution in the Roman Imperial Fleets", in A Companion to the Roman Army, ed. by P. Erdcamb, Oxford, 2007.

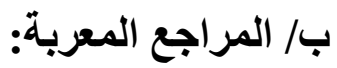

- ألفربد لوكاس: المواد والصناعات عند قدماء المصربين، ترجمة/ زكي إسكندر ومحمد زكريا غنيم، مراجعة عبد الحميد أحمد، القاهرة: دار الكتاب المصريَ، - 999

- ستيفن رنسيمان: الحضارة البيزنطية، ترجمة/ عبد العزيز توفيق جاويد، الهيئة المصرية العامة للكتاب، القاهرة، 99 (م.

- غوليام ناردوتشي: استبطان برقة قديمًا وحديثًا، ترجمة/ إبراهيم أحمد المهدي، ليبيا:

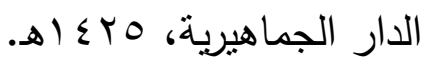

- ف. هايد : تاريخ التجارة في الثرق الأدنى في العصور الوسطى، ؛ أجزاء، ترجمة| أحمد محمد رضا، مراجعة/ وتقديم عز الدين فوده، الجزء الأول، القاهرة، الهيئة المصرية العامة للكتاب، 910 (م. 


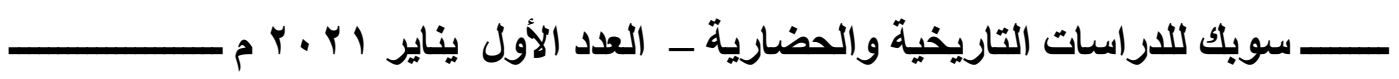

- مذكرات إيربن: ترجمة/ رودلف مرقس يني، مجلة مدارس الأحد، القاهرة، بيت

مدارس الأحد، اب79 (م، السنة الخامسة عشرة، العدد الثامن، عدد أكتوبر.

ج/ المراجع العربية

- خالد العاني: " الأسطرلاب "، جمعية هواة القلك السورية، سوريا ، د.ت.

- داود حلاق: مرقس الإنجيلي، بنغازي، دار الكتب الوطنية، بو99 (م،.

- مصطفى كمال عبد العليم، تاريخ لبييا القديم، بنغازي، المطبعة الأهلية، 977 (م.

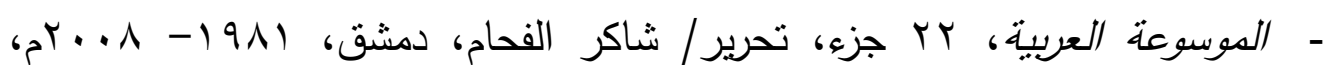
الجزء الأول، الإسطرلاب.

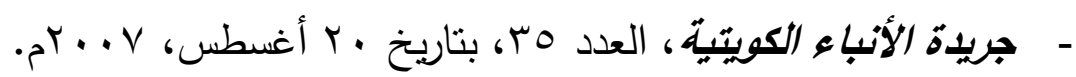

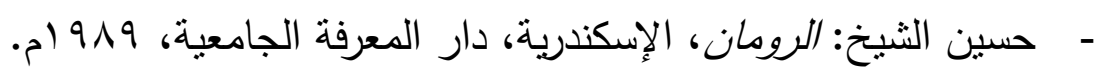

- شنودة الثالث: مرقس الرسول القدبس والثقيل، ط ج، القاهرة، 997 ام. - عبد العزيز طريح شرف: جغرافيا ليبيا، الطبعة الثانية، الإسكندرية: منشأة المعارف، . 9 )

- محمد مصطفى بازامة: بنغازي عبر التاربخ، جزءان، ليبيا، دار ليبيا للنشر

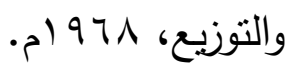

- محمود سعيد عمران: بحوث في تاربخ العصور الوسطى، الاسكندرية، دار المعرفة

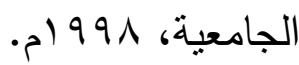
- ميخائيل مكسي إسكندر : تاريخ المسيحية وآثارها في الخدس مدن الغربية، ط باه،

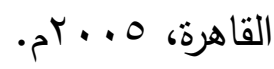

